\title{
A Bioleaching Regeneration and Recovery of Spent Refinery Catalyst Using Adapted Microorganisms
}

Olalere Olusegun Abayomi ${ }^{1}$, Olunusi Samuel Olugbenga ${ }^{2 *}$, Agboola John Olatunji ${ }^{3}$, Mohamed Farag Twibi ${ }^{1}$ and Saber Abdulhamid Alftessi ${ }^{1}$

${ }^{1}$ Chemical and Natural Resources Engineering, University Malaysia Pahang, Malaysia

2Industrial and Production Engineering, University of Ibadan, Nigeria

${ }^{3}$ Pure and Applied Biology, Ladoke Akintola University of Technology, Ogbomoso, Nigeria

\begin{abstract}
The regeneration of spent catalyst is either through chemical leaching or bioleaching techniques; with the latter being an alternative to the traditional extraction methods involving the use of series of adapted microorganisms. The bioleaching process is therefore the best alternative due to cost effectiveness, simple in operation and higher recovery of heavy metals. This research work adapted various microorganisms (three bacteria and one fungus) both singly and in mixture into a digested solution of a spent refinery catalyst. The activity order of the adapted microorganisms was described in this order; Pseudomonas flourescens $>$ Bacillus coagulans $>$ Bacillus megaterium or Pseudomonas putida>Fusarium flocciferum. The $\mathrm{Pb}$-ion showed a greater resistance to bioleaching while $\mathrm{Mn}$ ion was easily bioleached by the adapted microorganisms. From the results obtained, the affinity of some of these cultured microorganism strains to the heavy metals was attained with Fusarium flocciferum showing affinity for Mn only, Bacillus megaterium or Pseudomonas putida for $\mathrm{Mn}$ and $\mathrm{Cd}$-ions, Bacillus coagulans for $\mathrm{Pb}$ and partially for $\mathrm{Ni}$ - ion, while Pseudomonas flourescens for $\mathrm{Pb}$ and $\mathrm{Cd}$-ions. Hence the adaptation of various microorganisms into a digested solution of a spent refinery catalyst already poisoned with the heavy metals is explicitly carried out to regenerate the catalyst for a possible reuse which is optimal in saving the cost of production.
\end{abstract}

Keywords: Regeneration; Spent catalyst; Heavy metals; Bioleaching; Adapted microorganisms; Pseudomonas flourescens; Bacillus coagulans; Bacillus megaterium or Pseudomonas putida; Fusarium flocciferum

\section{Introduction}

Large quantities of catalysts are used yearly in petroleum refining and purification of various petroleum products. The quantity of these spent catalysts discarded increasingly posed a great danger to our environments [1]. These solid wastes from the refinery have therefore increased significantly in recent times and this could be attributed to the increase in the processing of high carbon chained feedstock.

The petroleum refining industry makes extensive use of catalysts for desulphurization of various fractions [2]. During hydrodesulphurization the catalysts are deactivated by compounds of $\mathrm{S}, \mathrm{C}, \mathrm{V}, \mathrm{Fe}, \mathrm{Ni}, \mathrm{Si}$ and traces of As and P. As a result, the spent catalysts are classified as hazardous materials, and due to higher concentration of these heavy metals in the spent catalysts they become toxic to the environment when dispose and thereby contaminate the ground water which is delicate to the populace.

However, such waste materials containing high metal concentrations may be considered as 'artificial or alternative ores' since they can serve as secondary raw materials with a consequent reduction in demand for primary mineral resources, cost reduction in acquiring a new catalyst, a less toxicity on the environment at least to the toxicity characteristic leaching procedure (TCLP) regulated level. Therefore, regeneration of spent catalysts became an unavoidable task [3].

A variety of processing approaches for regenerating spent catalyst from the contaminated heavy metals and carbon has been carried out [4]. The approaches are either by subjecting the spent hydro treating catalyst to chemical leaching (Hydrometallurgical and Hydro-pyro metallurgical processes) or using bioleaching method in regenerating the spent catalysts $[5,6]$. The latter is considered simpler and cheaper in operation, higher recovery of metals, and no involvement in direct attack on the catalyst. Bioleaching approach makes use of the capacity of different microorganisms to mobilize and leach metals from hazardous wastes on the basis of transformation of organic or inorganic acids, oxidation and reduction reactions; and excretion of complex agents. This has been proved to consistently result in the high metal-leaching efficiency. The corresponding higher yield noticeable in bioleaching when compare to chemical leaching may be as a result of the bioaccumulation that occurs in the presence of biomass.

Investigated the kinetics of bioleaching of $\mathrm{Mo}, \mathrm{Ni}$, and $\mathrm{Al}$ from spent catalyst, using adapted Aspergillus niger. Four regeneration variables were considered using central composite design (CCD) for the experimental design. An optimal regeneration variables were obtained for the particle size $(150-212 \mu \mathrm{m})$, sucrose $(93.8 \mathrm{~g} / \mathrm{L})$, pulp density $(3 \% \mathrm{w} / \mathrm{v})$, and $\mathrm{pH} 7$ with maximum metal recoveries at $99.5 \pm$ $0.4 \% \mathrm{Mo}, 45.8 \pm 1.2 \% \mathrm{Ni}$, and $13.9 \pm 0.1 \% \mathrm{Al}$.

Employed acidophilic bacteria in the leaching of Nickel, vanadium and molybdenum contained within spent catalyst. The study was conducted through the variation of the reaction time, quantity of spent catalysts, quantity of elemental sulfur and temperature. It was then concluded that the recovery of Nickel was the most significant recovery for the bioleaching process resulting in a leaching efficiency of $94.8 \%$ was obtained, at $1-2 \%(\mathrm{w} / \mathrm{v})$ spent catalysts concentration.

The objective of this study was to characterize of the catalyst samples to determine the metal concentration and isolate the adapted microorganisms from mechanic/welder soil for the regeneration

\footnotetext{
Corresponding author: Olunusi Samuel Olugbenga, Industrial and Production

Engineering, University of Ibadan, Nigeria, Tel: +2348034432126; Fax +2348073432536; E-mail: olabayor@gmail.com
}

Received June 13, 2016; Accepted August 27, 2016; Published October 30, 2017

Citation: Abayomi OO, Olugbenga OS, Olatunji AJ, Twibi MF, Alftessi SA (2017) A Bioleaching Regeneration and Recovery of Spent Refinery Catalyst Using Adapted Microorganisms. J Adv Chem Eng 7: 158. doi:

10.4172/2090-4568.1000158

Copyright: (๑) 2017 Abayomi OO, et al. This is an open-access article distributed under the terms of the Creative Commons Attribution License, which permits unrestricted use, distribution, and reproduction in any medium, provided the original author and source are credited. 
process. The bioleaching studies by the adapted microorganisms. This study elucidated the leaching of heavy metals from spent refinery catalyst using various adapted microorganisms in batch cultures. The significance of this research work is the comparative study of activity of different adapted microorganism in the regeneration of spent refinery catalyst.

\section{Materials and Methods}

\section{Apparatus and reagents}

The following under listed apparatus and reagents were engaged during the laboratory work: Conical flasks, Beakers, Measuring cylinder, Charcoal pot, Crucibles, Syringes, Sensitive weighing balance, Spatula, Charcoal, Round bottom flask, Incubator, Oven, Spirit lamp, Wire loop, Bottles, Autoclave, Ethanol, Nutrient Agar (NA), Electric Shaker, Potato Dextrose Agar (PDA), Chemical Salts, Distilled water, Refrigerator, High performance liquid Chromatography (HPLC), Cotton wool, Atomic Absorption Spectrometer, Petri dishes, and Mineral Acids Reagents.

\section{Preparation of catalyst and soil samples}

The spent catalyst samples are small round grains of about $1.2 \mathrm{~mm}$ in diameter which were grounded to increase the surface area. The soil samples were collected from different automobile mechanic and welder workshops.

\section{Digestion processes}

Digestion process was employed to destroy the organic matter contained in the spent catalyst by oxidation with the metal finally being brought into their ionic forms. It involves preparation and dissolution of the spent catalyst, separation and determination of metals. Digestion processes can be carried out either on wet basis using acids or dry basis using heat. The wet digestion was used in the preparation of our spent catalyst in acidic medium.

Procedures for wet acid digestion method: Six round-bottom flasks were washed and rinsed by the distilled water, dried in a furnace and cool at room temperature $\left(25^{\circ} \mathrm{C}\right)$. A spent platinum-molybdenum $(0.5 \mathrm{~g})$ was then weighed into the individual six round-bottom labeled flasks (labeled A to F). Sample a contained $10 \mathrm{ml}$ of hydrogen peroxide and $10 \mathrm{ml}$ of hydrochloric acid while sample $\mathrm{B}$ has $10 \mathrm{ml}$ of hydrogen peroxide plus $10 \mathrm{ml}$ tetraoxosulphate (IV) acid. To sample C was added $10 \mathrm{ml}$ of hydrogen peroxide and $10 \mathrm{ml}$ Trioxonitrate (V) acid; to sample D, $10 \mathrm{ml}$ Perchloric Acid and $10 \mathrm{ml}$ Trioxonitrate (V) acid; to sample E, $10 \mathrm{ml}$ Trioxonitrate (V) acid plus $10 \mathrm{ml}$ hydrochloric acid; to sample F, $10 \mathrm{ml}$ Perchloric acid plus $10 \mathrm{ml}$ tetraoxosulphate (IV) acid added respectively.

The samples were then placed inside the oven for 9 hours until they were all digested. All these were left, covered with cotton wool to prevent evaporation, deliquescence or the likes overnight for predigestion to take place. Furthermore, $1 \%(0.5 \mathrm{ml})$ of each digested samples was diluted in $99 \%$ (49.5 ml) of distilled water. An Atomic Absorption Spectroscopic (AAS) analysis was then performed to identify the heavy metal from the spent catalyst. After conducting the analysis, four different metals were identified from the crushed contaminated spent catalyst. These include; Nickel (Ni), Cadmium $(\mathrm{Cd})$, Lead $(\mathrm{Pb})$, and Manganese (Mn).

Isolation of microorganism: Soil samples were then collected from a mechanic and welder workshops to grow the microorganism strains. $1 \mathrm{~g}$ of soil sample were introduced into $9 \mathrm{ml}$ of sterile distilled water and shake rigorously and allowed to settle down for $2 \mathrm{hrs.} 1 \mathrm{ml}$ of soil suspension was inoculated into the media (NA and PDA) and both media were incubated at room temperature for PDA and NA at $37^{\circ} \mathrm{C}$. Pure strains of the micro-organisms were obtained by series of sub-culturing and the strains were then adapted to utilize three metals $(\mathrm{Pb}, \mathrm{Ni}$, and $\mathrm{Cd})$. The fittest strains were kept inside slant bottles and inside glycerol broth for preservation.

Preparation of solid media with toxic metal: This is the process of serial acclimatization of the fungus with the desired metal salts of known concentrations. This was performed in Petri dishes containing the solid growth medium. The Petri- dextrose agar (PDA) and nutrient agar (NA) were prepared in a specified quantity of distilled water by standardizing the medium solution using $39 \mathrm{~g} / \mathrm{l}$ and $28 \mathrm{~g} / \mathrm{l}$ respectively. Each metal $(\mathrm{Pb}, \mathrm{Mg}, \mathrm{Mn}, \mathrm{Cd}, \mathrm{Ni}, \mathrm{Cu}, \mathrm{Zn})$ salts were introduced into the broth using $0.75 \mathrm{~g} / \mathrm{ml}$ of distilled. The organism's strains were subcultured into series of media prepared, until pure strains were obtained. Another set of media were prepared with three different metals (Cd, Ni and $\mathrm{Pb}$ ) salts using $0.03 \mathrm{~g} / \mathrm{ml}$ for each metal and individual pure strains were consequently adapted to the media.

Minima salt medium (MSM) was prepared for the bioleaching processes on each of the specimen, the duplicate and the control using the following composition in the solution as follows; Yeast extract broth $(0.64 \mathrm{~g}), \mathrm{KH}_{2} \mathrm{PO}_{4}(0.2 \mathrm{~g}), \mathrm{KCl}(0.01 \mathrm{~g}), \mathrm{NaNO}_{3}(0.6 \mathrm{~g})$, distilled water $(400 \mathrm{ml})$, Glucose $(40 \mathrm{~g})$ and $\mathrm{MgSO}_{4} .7 \mathrm{H}_{2} \mathrm{O}(0.01 \mathrm{~g})$. Three sets of MSM were prepared, two containing the spent catalyst as specimen and duplicate, the third one without spent catalyst as a control.

\section{Bioleaching studies}

The adapted microorganisms were introduced into the spent catalyst for the leaching process. The state and growth of the microorganisms were noticed and recorded.

Bioleaching studies for bacteria strains: The stored pure strains of adapted bacteria were inoculated into a NA medium without toxic metal. The plates were stored inside incubator at $37^{\circ} \mathrm{C}$ temperature for $36 \mathrm{hrs}$ after which a growth is noticed with little sample of it taken with a wire loop, washed in $5 \mathrm{ml}$ sterile distilled water and shake rigorously for uniformity. $1 \mathrm{ml}$ of the inoculated sterile distilled water was introduced into $20 \mathrm{ml}$ of MSM solution with spent catalyst (specimen and duplicate) while same volume was introduced into the control.

Samples were taken from the specimen at $12 \mathrm{hrs}, 24 \mathrm{hrs}$, and $36 \mathrm{hrs}$ intervals then centrifuged to collect the solution and leftover residue beneath. $2 \mathrm{ml}$ is taken out of the solution with $33 \mathrm{ml}$ of distilled water for AA Spectroscopic analysis. The spent catalyst residue was digested and test for heavy metal concentration. An AAS analyzed results were then compared with the concentration of metal before bioleaching.

Bioleaching studies for fungi strains: The stored pure strains of adapted fungi were inoculated into PDA medium without toxic metal and the plate was stored inside incubator at room temperature for 72 hrs after which a growth was noticed. A Cork borer was put into use to pick the fungi and introduced into $20 \mathrm{ml}$ of specimen, duplicate and the control. The inoculums were kept in an incubator at $25^{\circ} \mathrm{C}$ with continuous rigorous shaking.

Samples were taken from the specimen at intervals of $0 \mathrm{hrs}, 24 \mathrm{hrs}$, $48 \mathrm{hrs}$, and $72 \mathrm{hr}$. These were then filtered to collect the spent catalyst residue and the cells (if found). $2 \mathrm{ml}$ of the filtrate was later diluted with $33 \mathrm{ml}$ of distilled water for AAS analysis. The biomass were collected dried overnight and weighed. The spent catalyst residue was digested and test for heavy metal concentration. The AAS analyzed results were then compared with the concentration of metal ions in the formal results. 


\section{Results and Discussion}

\section{Results analysis}

Raw spent digested catalyst was analyzed for heavy metal concentration which result serve as a measure for the result obtained for the bioleaching studies between digested catalysts. This comparison is depicted in Tables 1-5. From the characterisation test of microorganisms' samples the following bacteria and fungi species were identified as ${ }^{13} \mathrm{~B}$-Bacterium species Either Bacillusmegaterium or Pseudomonasputida, ${ }^{14} \mathrm{~B}$-Bacterium specie-Bacilluscoagulans, ${ }^{15} \mathrm{~B}$-Bacterium specie-Pseudomonasflourescens and ${ }^{15} \mathrm{~F}$-Fungus species - Fusariumflocciferum.

Table 1 compares two results. The result of analysis of the raw spent catalyst and the bioleached spent catalyst by the adapted microorganisms. The bioleached spent catalyst collected and digested using $20 \mathrm{ml}\left(\mathrm{H}_{2} \mathrm{SO}_{4}+20 \mathrm{ml} \mathrm{H}_{2} \mathrm{O}_{2}\right)$.

More so, Figure 1 described the overall bioleaching degree before and after the research studies outcomes of the bioleaching studies for $\mathrm{Ni}$ have shown that none of the bacteria specimen was economically advisable to be used in leaching $\mathrm{Ni}$ ion. Consider Cd-ion, which was best bioleached using any of the bacteria specimen, but for $\mathrm{Pb}$-ion, only ${ }^{13} \mathrm{~B}$-bacterium is not advisable to be used. $\mathrm{Mn}$ ions were better leached using ${ }^{13} \mathrm{~B}$-bacterium, ${ }^{15} \mathrm{~B}$-bacterium and ${ }^{15} \mathrm{~F}$-fungi specimens.

Meanwhile, Tables 2-5 showed periodic concentration remaining of the bioleaching process of the filtrate by various adapted microorganisms. The subsequent metal ion concentration levels were found to have reduced gradually in $\mathrm{Pb}$ for ${ }^{14} \mathrm{~B}$ and $\mathrm{Cd}$ for ${ }^{13} \mathrm{~B}$; partially in $\mathrm{Mn}$ and $\mathrm{Ni}$ for ${ }^{14} \mathrm{~B}, \mathrm{Mn}, \mathrm{Pb}$ and $\mathrm{Cd}$ for ${ }^{15} \mathrm{~B}, \mathrm{Mn}$ and $\mathrm{Pb}$ for ${ }^{15} \mathrm{~F}$. And some behaved totally irrationally which could be as a result of metabolic activities, like $\mathrm{Cd}$ for ${ }^{14} \mathrm{~B}$, Ni for ${ }^{15} \mathrm{~B}, \mathrm{Ni}, \mathrm{Pb}$ and $\mathrm{Mn}$ for ${ }^{13} \mathrm{~B}$ and $\mathrm{Cd}$ and $\mathrm{Ni}$ for ${ }^{15} \mathrm{~F}$. ${ }^{15} \mathrm{~F}$-fungi specimen in the filtrate from Figure 2 showed the expected behavior for $\mathrm{Mn}$ ion from 0-48 hrs, while the concentration rose at $72 \mathrm{hrs}$. Concentration of $\mathrm{Cd}, \mathrm{Pb}$, and $\mathrm{Ni}$-ion rose at $48 \mathrm{hrs}$ beyond normal, which was not expected. Figures 2-5 showed the comparison bioleaching studies of the heavy metal concentration in the filtrate of different samples containing the bacteria and fungi specimen over time period.

\begin{tabular}{|c|c|c|c|c|}
\hline \multirow{2}{*}{} & \multicolumn{4}{|c|}{ Concentration of Heavy metal ions remaining } \\
\cline { 2 - 5 } & $\mathbf{N i}$ & $\mathbf{C d}$ & $\mathbf{P b}$ & $\mathbf{M n}$ \\
\hline $\begin{array}{l}\text { Digested Raw } \\
\text { Spent Catalyst }\end{array}$ & 0.0342 & 0.0266 & 2.4114 & 0.094 \\
\hline${ }^{13} \mathrm{~B}-$ Bacterium & 0.0977 & 0.0620 & 4.3088 & 0.0065 \\
\hline${ }^{14} \mathrm{~B}-$-Bacterium & 0.0330 & 0.0154 & 1.3418 & 0.1038 \\
\hline${ }^{15} \mathrm{~B}-$-Bacterium & 0.0362 & 0.0066 & 0.9352 & 0.0248 \\
\hline${ }^{15} \mathrm{~F}$-Fungus & 0.5955 & 0.4408 & 3.5463 & 0.0772 \\
\hline
\end{tabular}

Table 1: Comparison of bioleaching degree between digested raw spent catalyst AAS analysis results.

\begin{tabular}{|c|c|c|c|c|}
\hline Time (Hrs) & $\mathbf{M n}$ & $\mathbf{P b}$ & $\mathbf{N i}$ & $\mathbf{C d}$ \\
\hline 0 & 0.058 & 0.3795 & 0.1636 & 0.0257 \\
\hline 24 & 0.055 & 0.1619 & 0.0945 & 0.0279 \\
\hline 48 & 0.03 & 3.2251 & 0.269 & 0.1476 \\
\hline 72 & 0.0796 & 0.0144 & 0.1204 & 0.01 \\
\hline
\end{tabular}

Table 2: ${ }^{15} \mathrm{~F}$ Periodic concentration remaining using AAS analysis.

\begin{tabular}{|c|c|c|c|c|}
\hline Time (Hrs) & $\mathbf{M n}$ & $\mathbf{P b}$ & $\mathbf{N i}$ & $\mathbf{C d}$ \\
\hline 12 & 0.0005 & 0.0328 & 0.0601 & 0.0382 \\
\hline 24 & 0.098 & 0.435 & 0.1094 & 0.014 \\
\hline 36 & 0.0767 & 0.1596 & 0.0788 & 0.0072 \\
\hline
\end{tabular}

Table 3: ${ }^{13} \mathrm{~B}$ Periodic concentration remaining using AAS analysis.

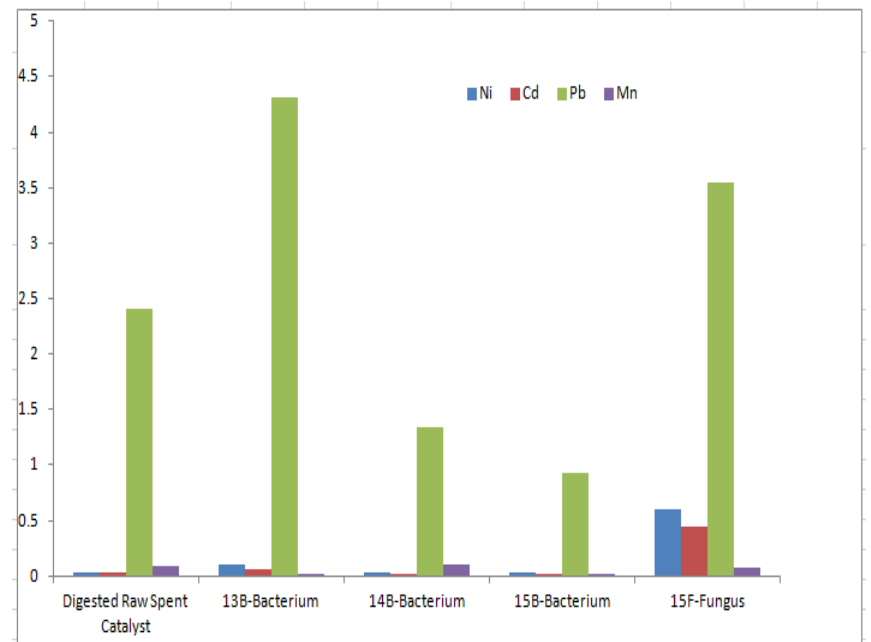

Figure 1: Description of bioleaching degree before and after bioleaching studies.

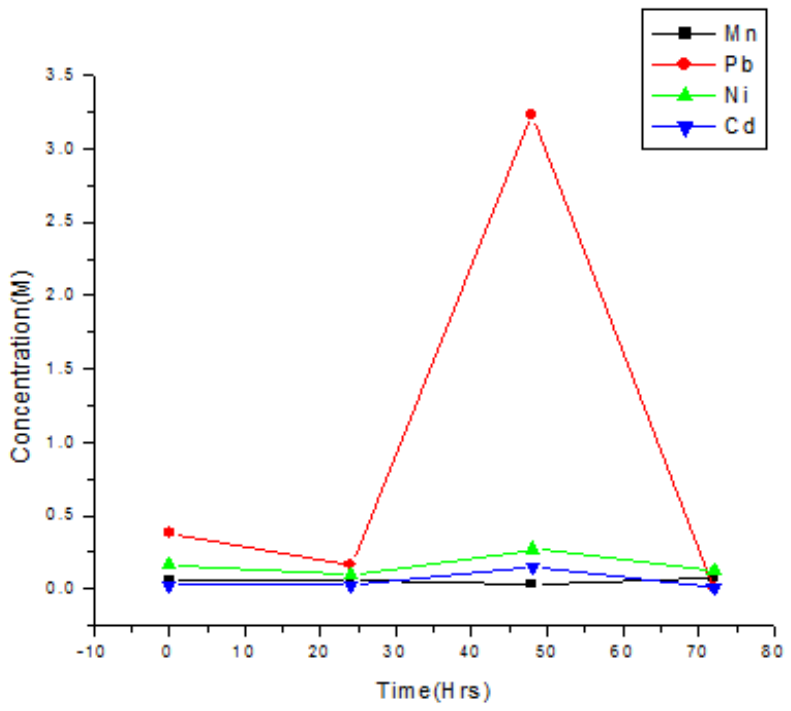

Figure 2: ${ }^{15} \mathrm{~F}$ Periodic concentration remaining using AAS analysis.

\begin{tabular}{|c|c|c|c|c|}
\hline Time (Hrs) & $\mathbf{M n}$ & $\mathbf{P b}$ & $\mathbf{N i}$ & $\mathbf{C d}$ \\
\hline 12 & 0.0569 & 0.4471 & 0.0053 & 0.1125 \\
\hline 24 & 0.0092 & 0.0353 & 0.0221 & 0.0028 \\
\hline 36 & 0.0259 & 0.128 & 0.106 & 0.1191 \\
\hline
\end{tabular}

Table 4: ${ }^{15} \mathrm{~B}$ Periodic concentration remaining using AAS analysis.

\begin{tabular}{|c|c|c|c|c|}
\hline Time (Hrs) & $\mathbf{M n}$ & $\mathbf{P b}$ & $\mathbf{N i}$ & $\mathbf{C d}$ \\
\hline 12 & 0.0709 & 0.1261 & 0.0968 & 0.0077 \\
\hline 24 & 0.0231 & 0.1052 & 0.017 & 0.0147 \\
\hline 36 & 0.0459 & 0.0213 & 0.0394 & 0.0121 \\
\hline
\end{tabular}

Table 5: ${ }^{14} \mathrm{~B}$ Periodic concentration remaining using AAS analysis.

Figure 3 showed the analysis result of ${ }^{13} \mathrm{~B}$-bacteria in the bioleaching process of the filtrate. It did not behave well for $\mathrm{Mn}, \mathrm{Pb}$, and $\mathrm{Ni}$ ions throughout the interval. But it behaved well for Cd-ion.

Figure 4 revealed the affinity of ${ }^{14} \mathrm{~B}$-bacteria for $\mathrm{Mn}$ and Ni-ion during the interval of 12-36 hrs while it behaved well for $\mathrm{Pb}$-ion throughout the intervals but its anomaly behavior was found for $\mathrm{Cd}$ ion. 
Figure 5 showed a sharp affinity of ${ }^{15} \mathrm{~B}$-bacteria for $\mathrm{Mn}$ and $\mathrm{Pb}$ ions between the interval of 12-36 hrs but behaved anomaly for both $\mathrm{Ni}$ and $\mathrm{Cd}$ ions concentration in the filtrate.

Actually, the graphs ought to decrease periodically but some anomalies surfaced. This might due to toxicity level of some of metal ions, metabolic activities and higher pulp density to the microorganisms in question.

\section{Conclusion}

This study involves the use of an adapted microorganism singly to leach and regenerate the heavy metals in the spent refinery catalyst. The activity order of the adapted microorganisms was described in this order; Pseudomonas flourescens $>$ Bacillus coagulans $>$ Bacillus megaterium or Pseudomonas putida $>$ Fusarium flocciferum (i.e., ${ }^{15} \mathrm{~B}>{ }^{14} \mathrm{~B}>{ }^{13} \mathrm{~B}>{ }^{15} \mathrm{~F}$ ). This depicted that the $\mathrm{Pb}$ - ion showed the highest resistance to leaching while $\mathrm{Mn}$ ion showed the least resistance. In

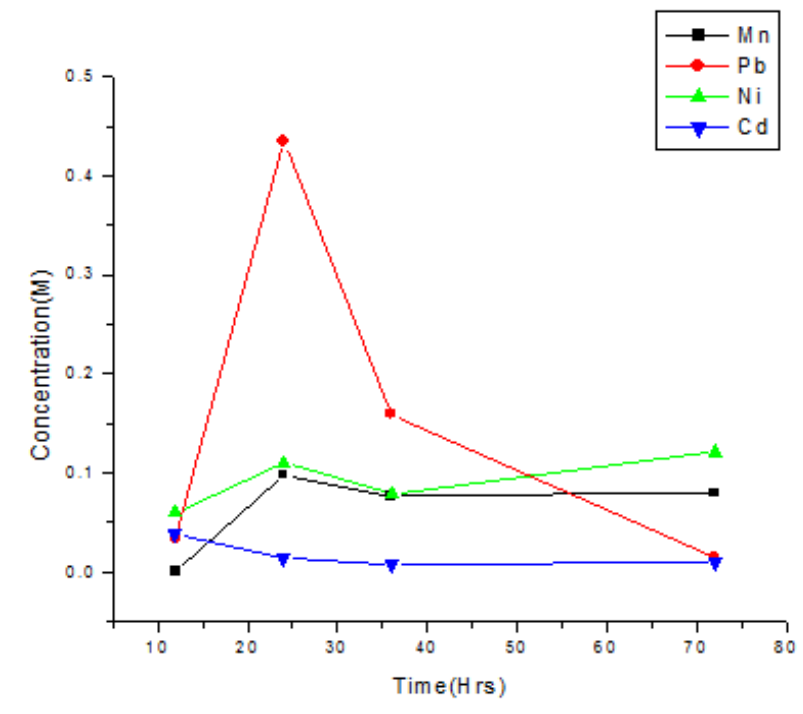

Figure $3:{ }^{13} \mathrm{~B}$ Periodic concentration remaining using AAS analysis.

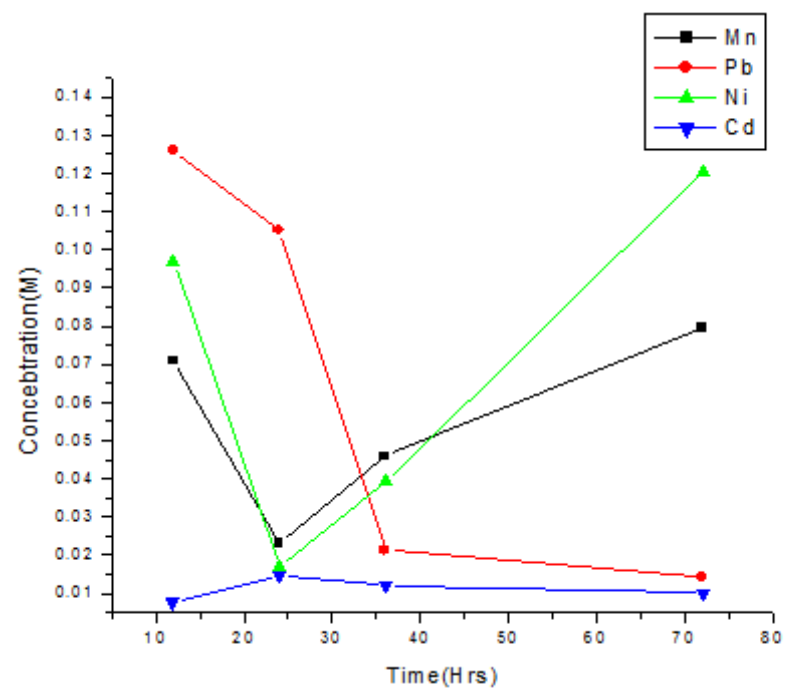

Figure 4: ${ }^{14} \mathrm{~B}$ Periodic concentration remaining using AAS analysis.

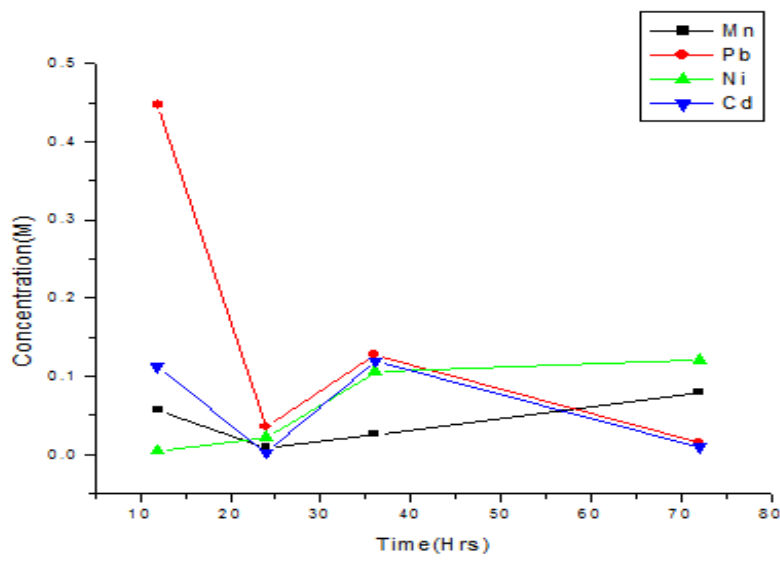

Figure 5: ${ }^{15} \mathrm{~B}$ Periodic concentration remaining using AAS analysis.

overall, the laboratory-scale bioleaching of the spent refinery catalyst using various adapted microorganism strains shows a promising first step towards bioleaching of a used substance. Considering the results obtained, it can be inferred out that the affinity of some of these cultured microorganism strains to the heavy metals; ${ }^{15} \mathrm{~F}$-fungi showed its affinity for $\mathrm{Mn}$ only, ${ }^{13} \mathrm{~B}$-bacteria for $\mathrm{Mn}$ and $\mathrm{Cd}$ ions, ${ }^{14} \mathrm{~B}$ - for $\mathrm{Pb}$ and partially for $\mathrm{Ni}$ ion, while ${ }^{15} \mathrm{~B}$ - for $\mathrm{Pb}$ ion. Further studies can be carried out on the extension of the bioleaching process for a minimum of thirty (30) days at a predetermined temperature $\left(30^{\circ} \mathrm{C}\right)$ and $\mathrm{pH}$.

This study helped in providing a means to reduce the global catalyst expenses, maximize its uses and application area, and protect the extensive environmental pollution and to minimize the industrial waste in the refinery.

\section{References}

1. Marafi M, Stanislaus A (2008) Spent hydroprocessing catalyst management: A review Part II. Advances in metal recovery and safe disposal methods. Resour. Conserv. Recycl. 53: 1-26.

2. Furimsky E, Massoth FE (1999) Deactivation of hydro-processing catalysts. Catalysis Today 52: 381-495.

3. Krebs W, Christoph B, Philipp PB, Reinhard B, Helmut B (1997) Microbial recovery of metals from solids. FEMS Microbial Rev 20: 605-617.

4. Ren WX, Li PJ, Geng Y, Li XJ (2009) Biological leaching of heavy metals from a contaminated soil by Aspergillus niger. Hazard Mater 167: 164-169.

5. Sun DD, Tay JH, Cheong HK, Leung DL, Qian G (2001) Recovery of heavy metals and stabilization of spent hydro-treating catalyst using a glass-ceramic matrix. J Hazard Mater 87: 213-223.

6. Deenan S, Yen-Peng T (2006) Use of Adapted Aspergillus niger in the bioleaching of spent refinery processing catalyst. Journal of Biotechnology 211: $62-74$. 